\title{
Lack of effect of specific sodium hunger on learned aversions to sodium and sucrose
}

\author{
AVA M. TRENT and JAMES W. KALAT \\ Duke University, Durham, North Carolina 27706
}

\begin{abstract}
Frumkin (1975) reported that sodium-deficient rats fail to learn taste aversions to $\mathrm{NaCl}$. However, those rats were sodium-deficient at the time of testing as well as at the time of training; any learned aversion could have been masked by a strong sodium hunger. Rats were made temporarily sodium-hungry by injections of Formalin or aldosterone. They were then poisoned after drinking both an $\mathrm{NaCl}$ and a sucrose solution. Several days later they were tested for learned aversions. Rats trained under the influence of aldosterone did not differ from controls. Rats trained under the influence of Formalin acquired slightly weaker aversions to both $\mathrm{NaCl}$ and sucrose. Thus there is no evidence that sodium deficiency alters the associability of $\mathrm{NaCl}$ with poison.
\end{abstract}

Rats which are poisoned after ingesting some substance acquire an aversion to the taste of that substance (Garcia, Ervin, \& Koelling, 1966; Garcia \& Koelling, 1966; Rozin \& Kalat, 1971). If a rat drinks more than one solution prior to poisoning, it may acquire a stronger aversion to one solution than to the other (Kalat \& Rozin, 1970). One determinant of the salience of various tastes in this situation is their novelty; rats which drink two solutions prior to poisoning acquire a stronger aversion to the more novel solution (Kalat, 1974; Revusky \& Bedarf, 1967).

Frumkin (1975) has recently proposed an additional determinant of how associable a taste is with poison. He reported that sodium-deficient rats learned much weaker aversions than normal rats if the taste of $\mathrm{NaCl}$ was paired with poison. Similarly, calcium-deficient rats learned weaker than normal aversions if calcium was paired with poison. Such results suggest a possible predisposition of rats to avoid associating a taste with poison while they have a specific hunger for that taste.

However, another, less interesting, interpretation is possible. Frumkin produced sodium deficiency and calcium deficiency by removal of the adrenal and parathyroid glands, respectively. Because these removals are permanent, the rats were sodium- or calcium-deficient at the time of testing as well as the time of training. It is certainly possible that these rats had learned aversions to sodium or calcium, but that the specific hungers for these minerals overrode the aversions (see Cullen, 1969; Rozin \& Kalat, 1971; Stricker \& Wilson, 1970). For analogy, if an experi-

Supported by research grants from Duke University and by an Angier B. Duke scholarship to the first author. Address reprint requests to J. W. Kalat, Department of Psychology, Duke University, Durham, North Carolina 27706. menter paired breathing with shock and the animals failed to stop breathing, it would not be proper to conclude that they had failed to learn.

In order to test the effect of sodium hunger on the associability of sodium with poison, it would be best to produce a temporary sodium hunger which could be present at the time of training but absent during the test. In Experiment 1, we produced temporary sodium deficiency by injections of Formalin. In Experiment 2, we produced sodium hunger without sodium deficiency by injections of aldosterone.

The experiments were designed to minimize one other possible problem in the interpretation of results. Suppose that sodium-deficient rats learned either a stronger or a weaker aversion to $\mathrm{NaCl}$ than the normal rats. A possible interpretation would be that the poison was either more aversive or less aversive, respectively, to the sodium-deficient rats. (The latter possibility is not totally implausible. It could be that when a rat is already ill, a further increase in illness might be less significant to the rat than if the rat had previously been healthy.) To avoid this problem, we poisoned sodium-hungry rats after they drank both a sucrose solution and an $\mathrm{NaCl}$ solution. We could conclude that sodium hunger altered the associability of $\mathrm{NaCl}$ only if the sodium-hungry rats showed either a stronger or weaker $\mathrm{NaCl}$ aversion than the controls, without showing a correspondingly stronger or weaker aversion to sucrose.

\section{EXPERIMENT 1}

\section{Method}

The subjects were 40 adult female rats, mean weight $285 \mathrm{~g}$, which had been born and reared in the authors' laboratory. The ancestry was mixed, consisting mostly of Sprague-Dawley albinos; however, pigmented rats were used preferentially for breeding, 
and most of the rats in this experiment were black, brown, or hooded. All rats were familiarized with $\mathrm{NaCl}$ prior to the experiment. For 6 consecutive days, their only access to liquid was a 30 -min presentation of $0.15 \mathrm{M} \mathrm{NaCl}$. Rats were assigned to four groups to balance the groups for sodium intake during this preliminary period.

On the following day, Day 0 , the deficient-poison $(n=11)$ and deficient-control $(n=8)$ groups were injected subcutaneously with $2 \mathrm{ml}$ of $1.5 \%$ Formalin $(0.6 \%$ formaldehyde in isotonic saline). Pilot studies in our lab and reports from other labs had indicated that these injections produce a reliable increase in sodium intake $8 \mathrm{~h}$ after the injections (Handel, 1965; Porter \& Relinger, 1972; Stricker, 1966; Stricker \& Wolf, 1966; Wolf \& Steinbaum, 1965). The nondeficient poison $(n=11)$ and nondeficient control $(\mathrm{n}=8)$ groups received $2 \mathrm{ml}$ injections of istonic saline at this time. Eight hours later, all rats were offered a $10 \%$ $(w / v)$ sucrose solution (unfamiliar to them) for $3 \mathrm{~min}$ in a $30-\mathrm{ml}$ graduated Richter tube. Fifteen minutes after introduction of the sucrose solution, a $0.15 \mathrm{M} \mathrm{NaCl}$ solution was presented, also for $3 \mathrm{~min}$. After another $15 \mathrm{~min}$, the rats in the two poison groups were intubated with $0.15 \mathrm{M} \mathrm{LiCl}, 1 \mathrm{ml}$ per $30 \mathrm{~g}$ body weight. Rats in the control groups received an analogous intubation with $0.15 \mathrm{M} \mathrm{NaCl} 2$ days later.

On Days 2-6, all rats were given distilled water for $30 \mathrm{~min}$ per day. Beginning on Day 7, all rats were tested for preferences for both sucrose and $\mathrm{NaCl}$. On Day 7 , half the rats in each group were offered tubes of sucrose solution and water, simultaneously, for $30 \mathrm{~min}$. The other half were offered $\mathrm{NaCl}$ solution and water. On Day 8, the rats previously tested for sucrose preference were tested for $\mathrm{NaCl}$ preference, and vice versa. This process was repeated on 10 consecutive blocks of 2 days.

\section{Results}

Figure 1 presents the median percent preferences for $\mathrm{NaCl}$ (above) and sucrose (below) over 10 extinction trials each. Intergroup differences were analyzed for Day 1, and for Days 1-10 combined, via the MannWhitney U test (two-tail). Both the deficient-poison and the nondeficient-poison groups showed a significant aversion to both sucrose and $\mathrm{NaCl}$, compared to the paired control groups, on both Day 1 and the combined Days $1-10$ ( $\mathrm{p}<.02$ in each case). There were no significant differences $(p>.05)$ between the two poison groups or between the two control groups.

It is apparent from Figure 1 that the aversion to sucrose extinguished faster than the aversion to $\mathrm{NaCl}$. An analysis of variance indicated that the interaction between solution and test day was significant for both the deficient-poison group $(F=27.03$, $\mathrm{df}=9,200, p<.02)$ and the nondeficient-poison group $(F=4.414, \mathrm{df}=9,200, \mathrm{p}<.02)$.

\section{Discussion}

Frumkin reported that sodium-deficient rats failed to learn an aversion to $\mathrm{NaCl}$ when $\mathrm{NaCl}$ consumption preceded illness. In the present experiment, rats

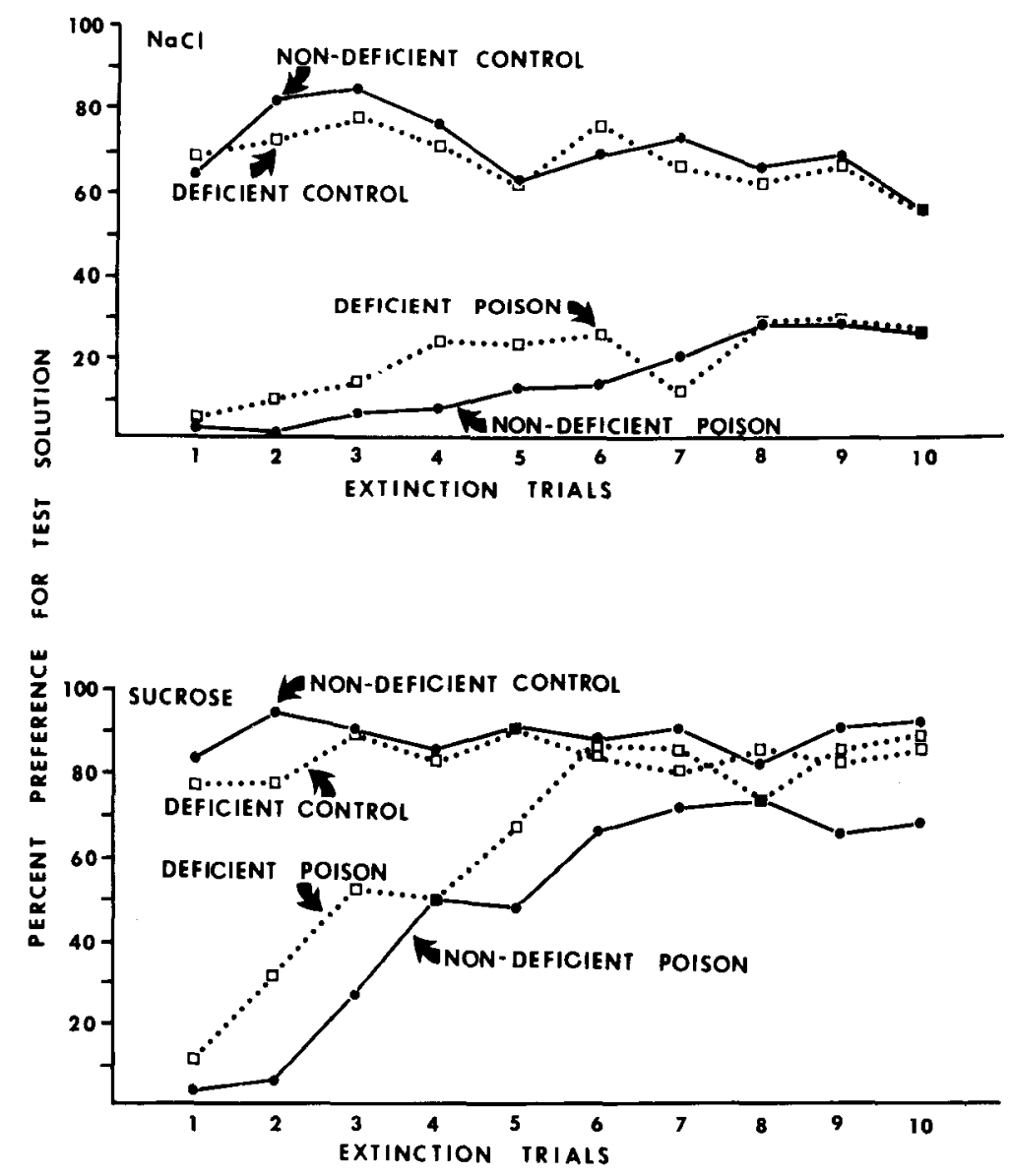

Figure 1. Median preferences for $\mathrm{NaCl}$ and sucrose during extinction trials, Experiment 1. 
which were sodium-hungry at the time of training but not at the time of testing acquired an aversion to $\mathrm{NaCl}$ that was just slightly weaker than that of rats which were not sodium-hungry.

This small difference could easily be due to chance. Even if it could be taken seriously, it need not indicate anything about a change in the associability of the taste of $\mathrm{NaCl}$. Formalin-injected rats acquired slightly weaker aversions to sucrose as well as $\mathrm{NaCl}$. Thus, it appears that the decrease in learned aversions of the sodium-hungry rats was not specific to salty tastes. Rather, it would be more consistent with the present results to suggest that lithium poisoning was less effective at inducing taste aversions if the poisoned animal was already sick at the time.

Experiment 2 is similar to Experiment 1, except that sodium hunger was induced by the hormone aldosterone instead of by Formalin injections. Aldosterone injections induce specific sodium hunger without sodium deficiency (Wolf, 1964). Also, just two extinction tests were conducted.

\section{EXPERIMENT 2}

\section{Method}

The subjects were 42 rats, mean weight $269 \mathrm{~g}$, from the same colony as in Experiment 1. Prior to the experiment, all rats were given water to drink for $1 / 2 \mathrm{~h}$ daily for 5 days.

The procedures on the training day (Day 0 ) were the same as in Experiment 1, except that there were aldosterone injections instead of Formalin injections. The aldosterone poison group $(n=14)$ and the aldosterone control group $(n=10)$ were given subcutaneous injections of $1.0 \mathrm{mg}$ of aldosterone (Sigma Corp.) in $0.25 \mathrm{ml}$ sesame oil. The nonaldosterone poison group $(\mathrm{n}=10)$ and the nonaldosterone control group $(n=8)$ were similarly injected with isotonic saline. After a $31 / 2-h$ delay, all rats were offered sucrose then $\mathrm{NaCl}$ solutions, and then intubated with $\mathrm{LiCl}$ (poison groups) or $\mathrm{NaCl}$ (controls), as in Experiment 1 .

On Days 1-3, all rats were offered water for $1 / 2 \mathrm{~h}$ daily. On Day 4, half the rats in each group were offered $\mathrm{NaCl}$ and water in separate tubes, simultaneously, for $1 / 2 \mathrm{~h}$. The other half were offered sucrose and water. On Day 5, the rats previously tested for $\mathrm{NaCl}$ preference were tested for sucrose preference, and vice versa. The procedures for Days 4 and 5 were repeated on Days 6 and 7, respectively.

\section{Results and Discussion}

Figure 2 presents the median intakes for $\mathrm{NaCl}$ (above) and sucrose (below) for each group on both days. Both of the poison groups showed a highly significant $(p<.002)$ aversion to both solutions on both days, compared to the controls. There were no significant differences $(p>.20)$ between the two experimental groups or between the two control groups for either solution on either day.

The data do not indicate any effect of the aldosterone injections on the associability of either $\mathrm{NaCl}$ or sucrose with $\mathrm{LiCl}$ poisoning.

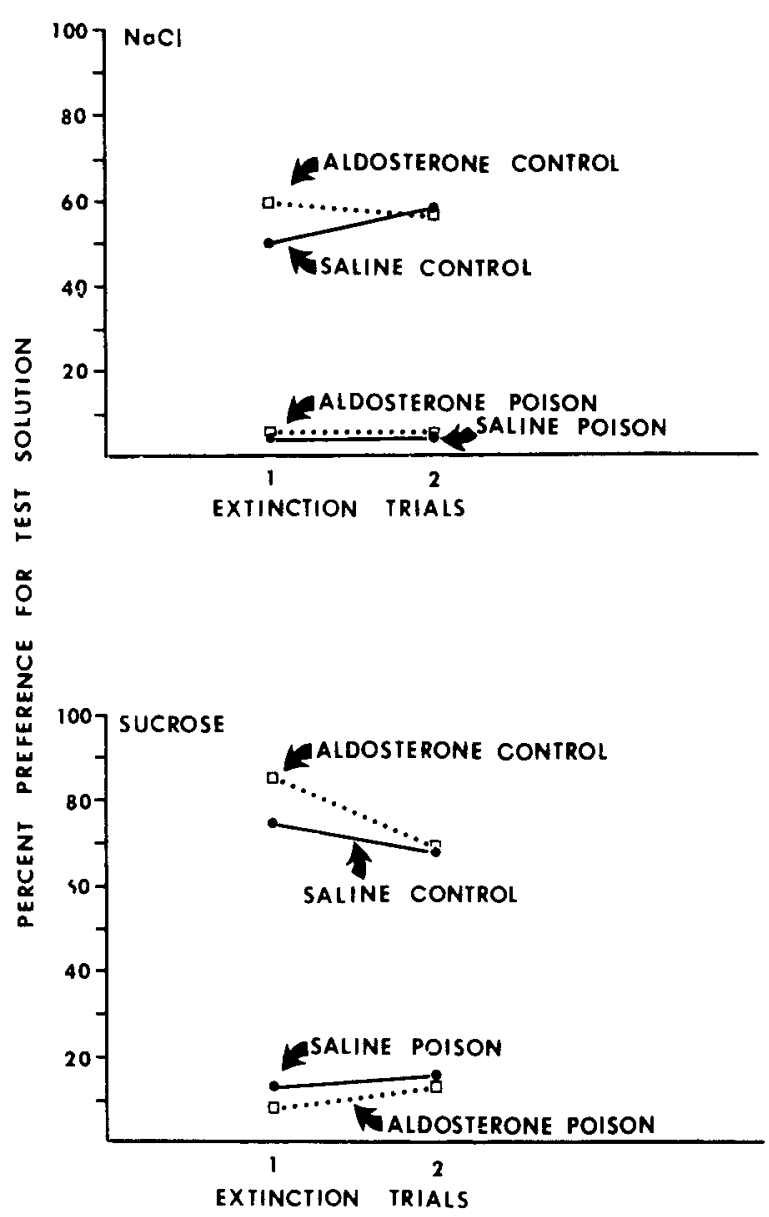

Figure 2. Median preferences for $\mathrm{NaCl}$ and sucrose during extinction trials, Experiment 2.

\section{GENERAL DISCUSSION}

Frumkin reported that sodium-deficient rats learn little or no aversion when $\mathrm{NaCl}$ taste is paired with poison. The present results fail to support this finding, using two means of inducing sodium hunger. The most obvious source of this discrepancy is that Frumkin's rats were tested for learned aversions to $\mathrm{NaCl}$ while they remained sodium deficient; our rats had several days to recover from the acute sodium hunger before testing began.

Although Formalin-treated rats in Experiment 1 demonstrated a slightly weaker aversion to sodium, these rats also showed a slightly weaker aversion to sucrose. Thus, the difference, even if reliable, might be due to decreased effectiveness of $\mathrm{LiCl}$ poisoning in animals already sick, rather than a specific effect on the salience of $\mathrm{NaCl}$. (Frumkin attempted to deal with this problem by including a group of adrenalectomized rats that were poisoned after drinking saccharin. However, more than three-fourths of the rats in this group died within 6 days after their first poisoning; it is difficult to interpret the low saccharin intakes of these obviously very sick rats.) 
In conclusion, there is at present no strong evidence that the associability of a particular taste with poison varies as a function of a rat's current specific hungers.

\section{REFERENCES}

CULlen, J. W. Modification of sait-seeking behavior in the adrenalectomized rat via gamma-ray irradiation. Journal of Comparative and Physiological Psychology, 1969, 68, 524-529.

Frumkin, K. Failure of sodium- and calcium-deficient rats to acquire conditioned taste aversions to the object of their specific hunger. Journal of Comparative and Physiological Psychology, 1975, 89, 329-339.

Garcia, J., ERvin, F. R., \& Koelling, R. A. Learning with prolonged delay of reinforcement. Psychonomic Science, 1966, 5, 121-122.

Garcia, J., \& Koelling, R. A. Relation of cue to consequence in avoidance learning. Psychonomic Science, 1966, 4, 123-124.

Handal, P. J. Formalin-induced sodium appetite: Dose-reponse relationships. Psychonomic Science, 1965, 3, 511-512.

KALAT, J. W. Taste salience depends on novelty, not concentration, in taste-aversion learning in the rat. Journal of Comparative and Physiological Psychology, 1974, 86, 47-50.

Kalat, J. W., \& Rozin, P. "Salience": A factor which can override temporal contiguity in taste-aversion learning.
Journal of Comparative' and Physiological Psychology, 1970, 71, 192-197.

Porter, J. J., \& Relinger, H. Daily sodium intake as a function of time of measurement and Formalin injection volume and concentration. Psychonomic Science, 1972, 26, 276-278.

Revusky, S. H., \& BEDARF, E. W. Association of illness with prior ingestion of novel foods. Science, 1967, 155, 219-220.

Rozin, P., \& Kalat, J. W. Specific hungers and poison avoidance as adaptive specializations of learning. Psychological Review, 1971, 78, 459-486.

STricker, E. M. Extracellular fluid volume and thirst. American Journal of Physiology, 1966, 211, 232-238.

STRICKER, E. M., \& WiLson, N. E. Salt-seeking behavior in rats following acute sodium deficiency. Journal of Comparative and Physiological Psychology, 1970, 72, 416-420.

STRICKER, E. M., \& Wolf, G. Blood volume and tonicity in relation to sodium appetite. Journal of Comparative and Physiological Psychology, 1966, 62, 275-279.

Wolf, G. Sodium appetite elicited by aldosterone. Psychonomic Science, 1964, 1, 211-212.

Wolf, G., \& Steinbaum, E. A. Sodium appetite elicited by subcutaneous Formalin: Mechanisms of action. Journal of Comparative and Physiological Psychology, 1965, 59, 335-339.

(Received for publication January 24, 1977; revision accepted March 7, 1977.) 